\title{
DESVIOS DA ÉTICA CORPORATIVA EM DECORRÊNCIA DA FRAGMENTAÇÃO DA REGULAÇÃO SOCIOAMBIENTAL BRASILEIRA: ANÁLISE DOS IMPACTOS SINERGICOS NA VOLTA GRANDE DO XINGU - PARÁ -AMAZÔNIA - BRASIL
}

\author{
Herena Neves Maués Corrêa de Melo*
}

\section{Resumo:}

O artigo tem como foco o caso da Mineradora Belo Sun e busca associar a discussão de ética nas corporações e o impacto do negócio em espaços amazônicos tendo por escopo evidenciar o desrespeito das companhias quanto às regulações internas que asseguram direitos humanos de populações tradicionais que vivem no entorno do território afetado. Deve-se prioritariamente reconhecer como consequência as violações de direitos humanos que são impostas aos grupos impactados pelos grandes empreendimentos que capturam os agentes públicos decisores dos processos de licenciamento, beneficiando-se da ausência da consolidação normativa socioambiental.

\section{Palavras-chave:}

ética corporativa, regulação socioambiental, violação de direitos humanos, impactos sinérgicos, Volta Grande do Xingu

DEVIATIONS FROM CORPORATE ETHICS DUE TO FRAGMENTATION OF THE BRAZILIAN SOCIO-ENVIRONMENTAL REGULATION: ANALYSIS OF THE SYNERGIC IMPACTS IN THE VOLTA GRANDE DO XINGU - PARÁ-AMAZÔNIABRAZIL

\section{Abstract:}

The article focuses on the Belo Sun Mining corp. searching to associates the discussion of ethics in corporations and the impact of the deal on Amazon for scope spaces highlight the disrespect that the companies have about the internal regulation standards that ensure human rights of traditional populations in the vicinity of the area affected. Should primarily recognize as a result human rights violations that are imposed on groups impacted by large enterprises that capture the government agent decision-makers of the environmental licensing process, taking advantage of the absence consolidating social-environmental.

\section{Keywords:}

corporate ethicssocial-environmental; regulation; violation of human rights; synergic impacts; Volta Grande do Xingu

\section{Introdução}

\footnotetext{
* Herena Neves Maués Corrêa de Melo - Bacharel em Direito (UFPA); Mestra em Direitos Humanos (PPGD/UFPA); Doutoranda em Desenvolvimento Sustentável do Trópico Úmido (NAEA/UFPA); Promotora de Justiça do Estado do Pará. Endereço Postal: Av. Conselheiro Furtado, 1934, AP 202, Cep: 66040-100 - Belém (PA); endereço de e-mail: herena1983@gmail.com
} 
A dignidade humana como princípio norteador das relações em sociedade é um princípio robusto nas legislações dos países que se autodeclaram democráticos. Inserida na lógica legislativa está a noção de ética empresarial, isto é, a conduta das corporações avaliando integralmente as consequências para os grupos interessados diretamente ou indiretamente no empreendimento.

A ética empresarial envolve princípios e arquétipos morais que orientam o desempenho no mundo dos negócios. É a partir da triagem dos diferentes grupos estratégicos que determinado comportamento será qualificado como ético ou antiético. Referidos grupos irão influenciar a aceitação ou a rejeição das condutas de uma empresa pela sociedade em que atua (Wood,1991; Reed,1999;Ferre 11, Fraederich e Ferrell, 2001).

O comportamento considerado ético seria, então, aquele que busca equilibrar os interesses econômicos d a empresa com os interesses dos demais participantes sociais. Seria, ao mesmo tempo, distinto do comportamento egoísta e do comportamento puramente altruísta, em que os próprios interesses são sacrificados em prol de outros (Rossouw, 2001 , p. 257 ; Huhn, 2014; p.527).

Neste passo, as grandes corporações empresariais originárias das nações qualificadas como desenvolvidas, têm por dever atuar segundo a evolução regulatória que inspira $\mathrm{m}$ as diversas democracias, acatando legislações sociais e ambientais, as quais historicamente provêm de uma paulatina construção em busca de um equilíbrio entre as necessidades de sobrevivência humana, desenvolvimento das economias e consequentemente dos Estados, todos ajustados, em última análise, no fundamento do bem - estar do ser humano.

Sucede que na atuação das grandes empresas, especialmente quando se observa a lógica d os grandes projetos, quando iniciam suas atividades em países em desenvolvimento, como no caso do Brasil, há o cumprimento de um raciocínio diferenciado, com a desatenção às legislações fundantes dos Estados democráticos, os s quais terminam por impor a indignidade e a vulnerabilidade aos seres humanos diretamente impactados, diante de uma visível insustentabilidade social.

Conforme ao norte exposto, reconhece - se a problemática da sociedade de risco pensada por Ulrich Beck, segundo o qual a sociedade de risco designa uma époc a em que os 
aspectos negativos do progresso determinam cada vez mais a natureza das controvérsias que animam a sociedade (Beck, 1991, p.371 ).

Nesta linha de análise, selecionou - se para o presente artigo o recorte dos grandes projetos para a Amazônia, mais e specificamente busca - se compreender o processo de licenciamento ambiental do "Projeto Volta Grande" de propriedade da Belo Sun minning corp., localizado no sudeste de Altamira, município brasileiro, região do rio Xingu, Amazônia (Amec, 2013 , p.23).

O projeto inicialmente previa a extração de 4,6 toneladas de ouro por ano, durante 12 anos, e a produção de milhares de toneladas de rejeitos tóxicos, que serão armazenados a 1 , $2 \mathrm{Km}$ do Rio Xingu. A mina, de acordo com o projeto, seria instalada a menos de $20 \mathrm{~K}$ m da barragem de Belo Monte e a $16 \mathrm{Km}$ da Terra I ndígena Arara da Volta Grande, área diretamente impactada pela usina de Belo Monte, sendo que os estudos ambientais da empresa permanecem sem indicar a sinergia dos impactos sobre as populações tradicionais e meio ambiente.

A partir da apreciação documental de parte do processo de licenciamento governamental, entende - se que há pujante ameaça à sobrevivência do meio ambiente, à vida e direitos humanos de índios e população tradicional na Volta Grande do Xingu.

Trata - se daquela que pode ser a maior mineração de ouro do Brasil e que obteve licença prévia e licença de instalação, por órgão do poder executivo estadual, carecedor de competência para a função segundo as leis brasileiras.

Desta feita, apreciaremos pareceres e manifestações na seara administrativa e judicial de membros do Ministério Público Federal e Ministério Público Estadual indicando a incompletude dos estudos de impacto ambiental, a fim de delinear as controvérsias acerca do descumprimento de fato res de regulação, que culmina no risco social e no risco de uma catástrofe ambiental, comparável ao que ocorreu no município de Mariana - MG.

Diante do esmiuçamento dos documentos, o que se apresenta mais estarrecedor é a incongruência das justificativas do órgão governamental licenciador, que insiste em não atender as próprias regras de regulação a cada passo do processo de licenciamento, invalidando as 
requisições de aprofundamento dos estudos necessários demonstrados pelo Ministério Público Brasileiro, pelo IBAMA e pela FUNAI.

Considerada pelos estudiosos, como André Villas Boas (2012 , p.34 ), Edna Castro, Sonia Magalhaes e Francisco del Moral Hernandes (2012 , p.56 ), como uma região de alto interesse para a conservação da biodiversidade, com fauna e flora ún icos, a Volta Grande será submetida a uma situação de estresse hídrico que pode decretar sua extinção.

Villas Boas explica que depois de tantas obras de infraestrutura realizadas na Amazônia ao longo de décadas, infelizmente não se logrou acumular aprendiz ados e desenvolver ferramentas adequadas para o planejamento da região.

Continua - se a persistir em incongruências quando, por exemplo, não se constrói previamente uma linha de base social, ambiental e econômica da bacia do Xingu, ou no mínimo da região diretamente afetada por Belo Monte para que se possa acompanhar e avaliar adequadamente todas as transformações em curso, corrigir o rumo das coisas, quando necessário.

\section{A fragmentação da legislação socioambiental e a conduta contrária a ética empresarial}

Em relação à hidrelétrica de Belo Monte, o Instituto Brasileiro de Meio Ambiente (IBAMA), através da Nota Tecnica (NT) nº129/2009 formulada e encaminhada pela Agência Nacional de Águas (ANA) tem conhecimento sobre a gravidade da situação da Volt a Grande e ambos estabeleceram um período de monitoramento de seis anos, no qual pode ser necessário, por exemplo, desviar menos água para as turbinas para assegurar a sobrevivência do rio.

Segundo a indigitada NT, em sua página 2. 668 do processo de licen ciamento de Belo Monte, a qual trata da navegação explica que o arranjo de Belo Monte não previa a transposição dos pedrões da Volta Grande. Admite, que o empreendimento não propiciará melhores condições de navegação em relação à atuais, já que o trecho nã o será inundado pelo reservatório.

Explica ainda, que interromper ou prejudicar muito essa navegação significa impedir as pessoas de se deslocarem para locais ao longo do próprio TVR, onde existem postos de saúde e escolas, como é o caso da Ilha da Fazenda e Ressaca, e mesmo para Altamira. É em 
Altamira que a população busca apoio para se tratar em casos mais sérios de doenças e, também, para onde levam os produtos de suas atividades econômicas para serem negociados. A diminuição das vazões provocará uma a lteração dos percursos de navegação, sendo necessárias escolhas de locais mais profundos e a existência de um mecanismo de transposição de barcos para se chegar à Altamira.

Mesmo com tamanha incerteza, as recomendações legais do Ministério Público Brasile iro foram desconsideradas e a empresa Belo Sun de mineração que faz a tramitação de seu processo de licenciamento pelo órgão estadual e logra êxito em obter por parte da Secretaria de estado Meio Ambiente e Sustentabilidade (SEMAS) a licença prévia e a lic ença de instalação, isto é, utilizando - se de normativas sistematicamente inconstitucionais, desconectadas com o contexto dos povos indígenas e populações tradicionais da Volta Grande do Xingu e ainda, desconsiderando a existência consolidada de impactos socioambientais decorrentes do funcionamento de Belo Monte, tenta a Belo Sun forçosamente demonstrar quadro de legalidade, este porém irreparavelmente desajustado dos limites da ética para com as comunidades diretamente interessadas.

Não há pronunciamento sobre a existência das comunidades indígenas, que vivem há gerações no ecossistema da Volta Grande, bem como de garimpeiros, que estão sendo sufocados e expulsos da área de forma ilegal., tendo, inclusive, a Defensoria Pública do Estado do Pará ingressado com ações objetivando a garantia de direitos fundiários, os quais foram violados pela empresa, a que também não se manifestou em seus estudos sociais sobre remanejamento destas pessoas.

O que se alcança ao analisar o procedimento regulatório do conteúdo de licencia mento ambiental do Projeto Volta Grande, Estado do Pará é o que Stigler (1971, p.3) descreve acontecer ao formular a teoria da Captura Regulatória " as a rule, regulation is acquired by the industry and is designed and operated primarily for its benefits" ${ }^{\circ} \mathrm{i}$

A análise da documentação da manifestação do órgão ministerial, especialmente a última recomendação do Ministério Público Federal, de 02 de fevereiro de 2017, cotejando - as com as respostas fornecidas pela Secretaria de Estado, Meio Ambiente e Sustentabilidade, seja na concessão da Licença Prévia, seja com a Concessão da Licença de Instalação à Empresa 
Belo Sun Minning corp., permite que seja formulada a seguinte pergunta: em que medida a fragmentação da regulação social e ambiental brasileira induz a violação local de direitos humanos assegurados globalmente pela conduta de corporações descompromissadas com a ética corporativa?

Dessa forma buscou - se identificar no procedimento legal de licenciamento ambiental a influência da fragmentação regulatória ante a ausência de participação qualificada no processo decisório de pessoas e povos diretamente afetados.

Foi também desenhado o conflito originado pela fragmentação regulatória resultante da definição recursos de poder entre os entes federativos, assim como demonstra - se as consequências da atuação da empresa em desatenção à ética coorporativa ao desconsiderar legislação em voga no Brasil.

A metodologia pautou - se na análise dos processos regulatórios governamentais e legais e nas legislações em vigor, desaguando em questões judiciais. No que tange ao método para o presente estudo, parte - se da pesquisa documental, da análise das manifestações do órgão regulador SEMAS e Ministério Público Estadual e Federal, bem como da legislação que diferencie os três níveis do pacto federativo existente no Brasil em relação à temática.

A hidrelétrica de Belo Monte, localizada fisicamente há $10 \mathrm{Km}$ do Projeto Volta Grande, foi em sua totalidade acompanhada, no que concerne ao licenciamento ambiental pelo IBAMA, órgão Federal, cuja competência se relaciona ao licenciamento ambiental como uma obrigação legal prévia à instalação de qualquer empreendimento ou atividade potencialmente poluidora ou degradadora do meio ambiente.

Referida movimentação em prol do licenciamento de atividades potencialmente poluidoras (BRASIL, 2016), possui como uma de suas mais expressivas características a participação social na tomada de decisão, por meio da realização de Audiências Públicas como parte do processo.

As principais diretrizes para a execução do licenciamento ambiental estão expressas na Lei 6.938/81 e nas Resoluções CONAMA nº 001/86 e n 237/97. Acerca das atribuições de licenciamento, há que se considerar também a Lei Complementar nº 140/2011, que ao discorrer 
sobre a competência estadual e federal para a autorização do empreendimento, tem como fundamento a localização do mesmo. Porém, quando há terra indígena na área de abrangência do grande projeto o órgão competente deve ser o federal, senão vejamos:

Art. $7^{\circ}$ São ações administrativas da União:

XIV - promover o licenciamento ambiental de empreendimentos e atividades: c) localizados ou desenvolvidos em terras indígenas.

A Diretoria de Licenciamento Ambiental é o órgão do IBAMA responsável pela execução do licencia mento em nível federal. Esta vem realizando esforços na qualificação, organização e automação dos procedimentos de licenciamento ambiental, e para tanto, disponibiliza aos empreendedores módulos eletrônicos de trabalho e ao público em geral, inúmeras informações sobre as características dos empreendimentos, bem como a situação do andamento do processo (IBAMA, 2016).

No entanto, a Belo Sun Mining Corp. empresa que objetiva explorar o ouro através do Projeto Volta Grande ignora a questão e se baseia exclusiva mente em legislação questionável e hierarquicamente inferior, quando se compara aos objetivos da República Brasileira expressos no texto Constitucional de 1998 que fornece primazia aos direitos humanos e aos tratados de direitos humanos aos quais o Brasil seja signatário, como no caso da Convenção 169 da Organização Internacional do Trabalho.

Neste sentido, o empreendedor fundamenta seu pedido de licenciamento ao órgão estadual com base na Portaria Interministerial no 419 de 26/11/2011, cujo o Art.3 ${ }^{\circ}, \S^{\circ}$, I aduz o que segue:

Há presunção de interferência em terra indígena, quando a atividade ou empreendimento submetido ao licenciamento ambiental localiza - se em terra indígena ou apresentar elementos que possam gerar danos sócio - ambientais diretos no interior da terra indígena, que no caso informa um raio de $10 \mathrm{~km}$, na Amazônia Legal.

No Estudo de Impacto Ambiental apresentado à SEMAS, a Terra Indígena Paquinçamba estaria a 10,7 km, segundo a Nota Técnica nº 4472/GEMIN/CLA/DILAP/2013, o que autorizaria a desconsideração, de acordo com a Secretaria Estadual de Meio Ambiente e Sustentabilidade, da sobreposição dos impactos sinérgicos da hidrelétrica de Belo Monte e da 
Mineradora Belo Sun, posto que seriam insignificantes entre si, o que demonstra a ocorrência da ideia de Beck (1991 , p.377 ) sobre a minimização política dos riscos aos quais as sociedades industriais estão submetidas.

Segundo Ulrich Beck (1991, p.388), nas sociedades de risco as consequências do sucesso da modernização são tematizadas:

os riscos se tornam mais arriscados, pois as condições para seu cálculo e sua gestão fracassam em parte, e, correlativamente, altera - se o papel da ciência e da técnica. Nestas circunstâncias, cria - se um novo clima moral para a política, no qual valores culturais des empenham um papel central.

Ainda para o citado autor (BECK, 1991, p. 389), "perigos são fabricados de forma industrial, exteriorizados economicamente, individualizados no plano jurídico, legitimados no plano das ciências exatas, e minimizados no plano político ".

Então é exatamente no plano político que se percebe essa minimização dos riscos sociais e ambientais do projeto em apreço.

O fato é que as minimizações dos riscos, danos e impactos perceptíveis no processo de licenciamento do Projeto Volt a Grande são recorrentes em todos os grandes projetos previstos para Amazônia a partir da década de 70 e terminam por afetar toda uma proteção internacional global aos atores envolvidos localmente e vulnerabilizados.

Diante dos inúmeros exemplos desastrosos, no caso da Belo Sun e Projeto volta Grande, a SEMAS desconsidera nos pareceres de concessão de licença a utilização do arsênio e cianeto na calha do rio, entre outras questões carentes de estudo apontadas por IBAMA, FUNAI, MPF e MPE . O que se atinge é que o fato de não haver consenso entre os entes federados cada um opera a regulação de uma forma, inviabilizando a construção sólida de um plano de vida para os diretamente atingidos.

Ocorre que a partir de uma noção de Estado Democrático de Direito, temos o político submetido às leis, isto é, ainda que o conteúdo do político seja determinado pelo Estado, cumpre a este e a organização a fiel observância da Constituição e demais leis decorrentes dos princípios constitucionais. 
Apreende - se de uma lado a atuação (ação judicial e recomendação) do Ministério Público Federal, de outro o poder público do Estado do Pará através da SEMAS, priorizando a defesa do Estudo de Impacto Ambiental e Relatório de Impacto Ambiental apresentado pela Belo Sun, ao tornar insignificante todos os apontamentos de riscos catastróficos para o meio ambiente e população local diretamente afetada, que já foram, inclusive reconhecidas em sede sentença do juiz federal em Altamira anulou a licença prévia do empreendimento, em 2014.

No parecer da SEMAS (2013,p. 4), que concede a licença prévia há o claro descomprometimento com a sustentabilidade que engloba os aspectos sociais e ambientais, pois apesar de considerar como precários os indicadores socioeconômicos d escritos no EIA RIMA, bem coma a consequência de se expor à população aos diversos riscos de adoecimento, em razão do precário abastecimento de água, esgotamento sanitário e coleta de lixo, além do sistema educacional deficitário. Não há qualquer condicionamento da concessão da licença prévia a apresentação de dados técnicos precisos por parte da empresa para que esta seja monitorada em suas atividades.

O mesmo ocorre na licença $n^{\circ}$ 2712/2017, licença de construção/instalação inexiste qualquer dado que ateste o cumprimento das primeiras observações apontadas na Licença Prévia para que a sua concessão.

O MPF entrou com uma segunda ação judicial, ainda em 2014, reivindicando que o licenciamento seja feito pelo IBAMA, o que foi acatado em sede liminari ${ }^{\mathrm{ii}}$.

A empresa recorreu e aguarda julgamento pelo Tribunal Regional Federal da 1a Região, em Brasília. Este processo foi julgado em 09 de julho de 2019, sendo que a turma da justiça Federal modificou a decisão, reconhecendo a SEMAS como o órgão licenciador competente, porém havendo possibilidade de recurso, informação comunicada pela mineradora a todos os seus acionistas (BELO SUN, 2019)

Enquanto os processos aguardaram julgamento, as duas decisões das Justiça Federal em Altamira permaneceram suspensas ${ }^{\mathrm{iii}}$ e o licenciamento continuou perante o órgão ambiental estadual, sendo que a empresa se fundamenta exclusivamente em na portaria interministerial acima exposta, devendo inclusive esse ato normativo ser submetido a um 
controle de convencionalidade em face de convenções internacionais de direitos humanos ao qual o Brasil seja signatário.

Para além da legislação fragmentada brasileira, que admite a grandes empresas como a Belo Sun corp. a insistência em uma conduta em desacordo com a ética empresarial, tem - se as consequências diretas as populações estabelecidas localmente, apontadas no processo de licenciamento pelo Ministério Público Estadual no Ofício no 096/2013 MP/CAOMA endereçado ao Secretário Estadual de Meio Ambiente, datado de 04.11.2013, portanto antes da concessão da licença prévia, no qual em sua segunda página dispõe que existem graves irregularidades no procedimento de licenciamento ambiental em apreço, as quais referem - se principalmente:

1. Ausência de estudos de impactos sobre os povos indígenas afetados pelo empreendimento;

2. Ausência de avaliação dos impactos sinérgicos do presente projeto em relação com o projeto da Usina Hidrelétrica de Belo Monte;

3. Incompetência do órgão ambiental estadual para o licenciamento ambiental;

4. Inobservância da Convenção $n^{\circ} 169$ da OIT.

Ademais na Recomendação nº1/2017/GAB1 de 02.02.2017, do MPF, há clara advertência à SEMAS da impossibilidade de concessão de licença da instalação para a mineradora canadense Belo Sun sem a construção de um Plano de Vida para as populações tradicionais moradoras do Trecho de Vazão Reduzida do Rio Xingu, mediante análise de sinergia e sobreposição de impactos, assim como impõe que a omissão quanto as providencias a serem tomadas implicam na responsabilização do Estado do Pará pelas consequências negativas da não adoção do princípio da precaução.

Ainda assim, a SEMAS ignora todas as recomendações do órgão ministerial, bem como tudo o que até o momento foi levado a seara judicial e sem qualquer compromisso efetivo da empresa no que tange à ética corporativa e cumprimento da legisl ação brasileira concede a licença de instalação.

Observa - se que desde reunião em que autora participou em dezembro de 2015, na sede da empresa na Volta Grande, com o Diretor - Presidente da Belo Sun do Brasil, Mauro Barros, representante do Sindicato de Garimpeiros da Vila Ressaca, representante da MAB, 
Promotor de Justiça do Estado responsável e representante do Estado do Pará, não houve qualquer mudança de cunho prático por parte da companhia.

Os representantes do empresariado participam, direta e indiretamente, no processo de licenciamento ambiental, colocando o governo do Estado como parceiro direto através da Secretaria Estadual de Desenvolvimento Minerário e Secretaria Estadual de Meio Ambiente e Sustentabilidade, essa participação política ocorre durante as etapas de tramitação de projetos de licenciamento, com o fornecimento de transporte a área da empresa de difícil acesso e diversas combinações em reuniões, retirando a isenção do órgão licenciador, que em última análise é o governo do Estado do Pará, ainda que através das secretarias.

Na citada reunião, que foi gravada por áudio pela pesquisadora, percebeu a parceria do Estado com a empresa que custeou transporte e acomodação para o Estado, bem como o discurso comum em prol do empresariado. Não havia qualquer plano de compensação na apresentação que foi feita para as populações locais.

Em 21 de fevereiro de 2017, a justiça estadual agrária de Altamira suspendeu a licença de instalação a pedido da Defensoria Pública do Estado do Pará em favor dos garimpeiros locais, em decorrência das irregularidades fundiárias e desassistência à população local.

\section{Principais conclusões: A identificação da teoria da captura regulatória no processo de licenciamento do Projeto Volta Grande em desacordo com a ética e responsabilidade corporativa.}

A ética e a responsabilidade social corporativa baseiam - se na noção de que as corporações possuem a obrigação de trabalhar para a melhoria do bem - estar social (Frederick, 1994, p.157 ). Wartick e Cochran (1985, p.758 ) elencam as duas premissas centrais deste conceito: (1) existe um contrato entre a organização e a sociedade, que funciona como um veículo por meio do qual o comportamento dos negócios é posto em conformidade com os objetivos da sociedade; (2) os negócios desempenham o papel de agentes morais dentro da sociedade, refletindo e reforçando seus valores. 
Por sua vez, os pensadores de maior destaque da teoria da Escolha Pública, na qual se insere a teoria da captura regulatória, Gordon Tullock e James McGill Buchanan Jr. mostraram que além das "falhas de mercado" existem as "falhas de governo". A teoria da escolha pública veio clarificar as "falhas do governo" e os limites da intervenção desse mesmo Estado.

Desta feita, a "captura regulatória" é uma das muitas possíveis "falhas de governo", originadas justamente do voluntarismo estatal para corrigir eventuais falhas do mercado, que ocorre quando um a agência reguladora, criada para atuar no interesse público, acaba atuando para favorecer grupos de interesses que dominam a indústria ou o setor que estaria encarregada de regular.

Os teóricos da escolha pública argumentam que captura regulatória, se não é inevitável, é altamente provável de acontecer em algum momento. Isso ocorre porque, como é fácil inferir, aqueles que são regulados detém poder em termos técnicos quanto econômicos, além de possuírem enorme interesse no resultado do trabalho dos reguladores, enquanto os supostos beneficiários da regulação encontram - se difusamente espalhados e desorganizados quando em comparação a uma organização.

Outra grande vantagem das empresas é o conhecimento especializado. Essa expertise permite que elas possam desvirtuar os fatos e os argumentos necessários para influenciar o regulador/legislador/fiscalizador. No caso da atuação da Belo Sun, há um aproveitamento da fragmentação da regulação social e ambiental, havendo pressão ao regulador na restrição do nível e da forma de regulação.

A partir do descompasso entre os entes federativos empresa afetada escolhe a norma a qual deseja se submeter, ignorando as demais e simulando a existência da l egalidade e atuação dentro de parâmetros éticos corporativos.

Ressalte - se que a existência de um regulador capturado é nefasta aos demais interessados num processo regulatório hígido, escorreito, pois concentra nas mãos os interesses particulares, utilizan do - se intencionalmente do poder discricionário do Estado, que em tese somente detém legitimidade para atuar em prol do interesse público. 


\section{Considerações finais}

Este trabalho teve como escopo principal analisar o procedimento legal de licenciamento ambiental do Projeto Volta Grande, de autoria da Belo Sun mining corp., demonstrando a atuação da empresa e do poder público regulador, sob a influência da fragmentação regulatória de cunho social e ambiental, descrevendo - se "falhas de governo" a partir da noção da teoria da captura regulatória.

O que se observa é a ausência de participação qualificada no processo decisório dos povos interessados diretamente afetados, em decorrência de uma atuação empresarial desconectada da lógica ética corporativa e uma oportunista forma de interagir com os entes federativos.

O rol documental pesquisado indicou um não alinhamento da corporação e do poder político e regulador estatal com a ética empresarial e por via de consequência ruptura com direitos humanos assegurados na estrutura constitucional e em âmbito global.

A pesquisa foi realizada em tempo real e a identificação do processo de captura do ente estatal por parte da empresa objeto da regulação ainda não pode ser considerada finalizada. No entanto, a violação local de direitos humanos globalmente assegurados e o comportamento oportunístico da empresa são fatos cuja evidência demonstra a ausência de ética na relação dessa empresa com os diretamente afetados por sua conduta.

\section{Referências}

ACSELR AD, Henri; MELLO, Cecília. Elementos para análise do RIMA de Belo Monte à luz das conclusões e recomendações do projeto Avaliação de Equidade Ambiental. In: MAGALHÃES, Sônia M. S. Barbosa; HERNANDEZ, Francisco del Moral (org.). Painel de Especialistas - Análise Crítica do Estudo de Impacto Ambiental do Aproveitamento Hidrelétrico de Belo Monte . Belém, 29 de outubro de 2009.

AGENCIA NACIONAL DE ÁGUAS - ANA. Nota Técnica acerca das condições de Navegabilidade e Estresse Hidrico do Rio Xingu com funcionamento de belo Monte . Brasilia, DF: Nota Tecnica (NT) nº129/2009. 1650 p. 
BECK, Ulrich. La politique dans la société du Risque. Revue du MAUSS , Paris, n. 17 p. 376 - 392, 2001.

. The reinvention of politics. Rethinking modernity in the global social order. Cambridge: Polity Press, 1997.

World risk society. Cambridge: Polity Press, 1999.

BRASIL. Constituição Federal (1998). 56. Ed. São Paulo:Saraiva, 2016.

BRASIL. Lei no 6.938 (1981). Vadmecum 40. Ed. São Paulo:Saraiva, 2015.

BRASIL. Resolução CONAMA n001 Lei no 6.938 (1986). Vadmecum 40. Ed. São Paulo:Saraiva, 2015

BRASIL. Resolução CONAMA n²37 (1987). Vadmecum 40. Ed. São Paulo:Saraiva, 2015

BUChanAn, James M. Better Than Plowing And Other Personal Essays . Chicago: University of Chicago Press, 1992.

CÂMARA TÉCNICA PERMANENTE DE RECURSOS HIDRICOS E MINERÁRIOS DA SEMA. Análise do Projeto Volta Grande - Belo Sun Mineração LTDA . Belém, PA: Protocolo no 2012/0000005028, Parecer Técnico nº 22520/GEMIN/CLA/DILAP/2013. 6 p. Parecer de concessão da Licença Prévia a Mineradora Belo Sun.

CASTRO, Edna. Expansão da Fronteira, Megaprojetos de Infraestrutura e Integração Sul Americana. CADERNO CRH, Salvador, v. 25, n. 64, p. 45 - 61, Jan./Abr. 2012.

FERNANDEZ, Maria Elizabeth Moreira. Direito ao ambiente e propriedade privada: aproximação apestudo da estrutura e das conseqüências das "leis - reserva" portadoras de vínculos ambientais. Coimbra: Coimbra Edi tora, 2001 .

FERREIRA FILHO, Manoel Gonçalves. Direitos Humanos Fundamentais. 6. ed. São Paulo:Saraiva, 2004. 
FERRELL, O. C.; FRAEDERICH, J.; FERRELL, L. Ética empresarial : dilemas, tomadas de decisão e caso s. Rio de Janeiro: Reichman \& Affonso, 2001.

FLICK, U. Introdução à pesquisa qualitativa. 3.ed. Porto Alegre: Bookman, 2009. . Introdução à metodologia de pesquisa. Porto Alegre: Pens o, 2013.

FREDERICK, W. C. From CSR1 to CSR2. Business and Society , v. 33, n. 2, p.150 - 164, 1994.

HUHN, M. . You reap what you sow: How MBA programs undermine ethics. Journal of Business Ethics, 121(4), 527 - 541, 2014.

MIGUEL, Juan Francisco Delgado de. Derecho agrário ambiental: propiedad y ecologia. Pamplona: Aranzadi, 1992.

MINAYO, Maria Cecí lia de Souza (org.). Pesquisa social: teoria, método e criatividade. 29. ed. Petrópolis, RJ: Vozes, 2010

MINISTÉRIO PÚBLICO DO ESTADO DO PARÁ. Relatório técnico CAOMA do MPE sobre graves irregularidades da Belo Sun. Belém, PA: Ofício nº96/2013 - MP/CAOMA. 13 p. Relatório do MPE ao Conselho Estadual de Meio Ambiente.

MINISTERIO DA JUSTIÇA E CIDADANIA. CONSEL HO NACIONAL DOS DIREITOS HUMANOS. Recomendação do Conselho Nacional dos Direitos Humanos - CNDH. Relatório do Grupo de Trabalho sobre população atingida pela implementação da UHE Belo Monte e pelo projeto de Intalação da Mineradora belo Sun. Brasília, DF: OF ÍCIO Nº74/2017/CNDH/GM/SDH/MJ. 2 p. Recomendação a SEMAS/PA.

MINISTÉRIO PÚBLICO FEDERAL. Recomendação Sobre A Impossibilidada De Concessão de Licença de Instalação a Mineradora Canadense Belo Sun Sem A Construção De Um Plano De Vida .Altamira, PA: Recomenda ção 01/2017/GAB1. 5 p. Recomendação MPF a SEMAS/PA.

MORAES, Alexandre de. Direitos Humanos Fundamentais. 3.e d. São Paulo: Atlas, 2000. 
MORAES, Alexandre de. Direito Constitucional.9. ed. São Paulo: Atl as, 2001. SCHIMITT, Carl. Teoria de la Constitución. Madrid: Alianza Editorial, 1996.

PEREIRA, Paulo Trigo. A teoria da escolha pública (public choice): uma abordagem neoliberal?. Análise Social , Lisboa, vol. xxxii (141), (2. $\left.{ }^{\circ}\right), 419$ - 442, 1997.

ROSSOUW, G. J. The scope of business ethics. South African Journal of Philosophy , v. 20 n. 3 , p. $257-269,2001$.

SOURCE, D R. Three Realms of Corporate Responsibility: Distinguishing Legitimacy, Morality and Ethics : Journal of Business Ethics, Vol. 21, No. 1, pp. 23 - 35, Aug., 1999.

STIGLER, George. Th e Theory of Economic Regulation . New York: The Bell Journal of Economics and management Science, volume 2, issue 1, pp3 - 2 1, spring 1971.

VILlAS BOAS, A. De Olho na Bacia do Xingu. São Paulo: ISA,, 2012. Disponível em: https://issuu.com/instituto - socioambiental/docs/de - olho - no - xingu . Acesso em 28.02.2017, 20:30.

WARTICK, S. L.; COCHRAN, P. L. The Evolution of the Corporate Social Performan ce Model . New York: Academy of Management Review , v. 10, n. 4, p. 758 - 769, 1985.

\footnotetext{
i Em uma tradução livre " como regra, o regulamento é caputurado (adquirido) pela indústria e é projetado e operado principalmente por seus benefícios".

ii Número do Processo em que se obteve a decisão liminar:2505 - 70.2013.4.01.3903

iii Decisão do Agravo de Instrumento que suspendeu a decisão de anulação do licenciamento: 001749 -

24.2015.4.01.000/PA .
} 